\title{
El trascendentalismo literario Entre cuba, república dominicana y puerto rico
}

\section{Literary transcendentalism \\ Between cuba, dominican republic and puerto rico}

DOI: $10.46932 / \mathrm{sfjdv} 2 \mathrm{n} 2-093$

Received in: March 1st, 2021

Accepted in: May 30th, 2021

\author{
Iván Segarra Báez \\ Catedrático Asociado \\ PhD. Filosofía y Letras Literatura de Puerto Rico y el Caribe, San Juan, Puerto Rico. \\ Departamento de Estudios Hispánicos; Pontificia Universidad Católica de Puerto Rico; Recinto de \\ Ponce, Puerto Rico. \\ E-mail: ivan_segarra@pucpr.edu; ivansegarra362@gmail.com
}

\begin{abstract}
RESUMEN
Este artículo intenta establecer el desarrollo del trascendentalismo literario y cómo se manifiesta entre las islas de Cuba, República Dominica y Puerto Rico desde los años de 1927 hasta mediados de 1950. El trascendentalismo literario fue una manifestación que contempló diversas ideologías y posturas entre nuestras islas caribeñas. A pesar de que este movimiento literario fue uno breve no dejó de sentar las bases para que los escritores del sesenta y setenta crearan diversas visiones del mundo en su contexto ideológico y social de finales de siglo XX. El estudio de este movimiento debe estar presente entre las generaciones venideras por sus repercusiones trasatlánticas dentro de la cuenca caribeña y la creación de mejores marcadores literarios del archipiélago caribeño en su contexto social y humanitario del siglo XXI. El trascendentalismo involucra un trabajo mayor que no se ha realizado todavía dentro de la literatura caribeña.
\end{abstract}

Palabras claves: Trascendentalismo, literatura, islas, movimientos, cultura, archipiélago

\begin{abstract}
This article attempts to establish the development of literature transcendentalism and how it manifests itself between the islands of Cuba, the Dominican Republic and Puerto Rico form the years 1927 to the mid-1950s.

Literary transcendentalism was a manifestation that contemplated various ideologies and positions among our Caribbean islands. Even though this literary movement was a brief one, it did not fail to lay the foundations for the writers of the sixties and seventies to create diverse visions of the world in their ideological and social context of the late twentieth century. The study of this movement must be present among future generations due to its transatlantic repercussions within the Caribbean basin and the creation of better literary markers of the Caribbean archipelago in its social and humanitarian context of the $21^{\text {st }}$ century. Transcendentalism involves a major work that has not yet been done within Caribbean literature.
\end{abstract}

Keywords: Transcendentalism, literature, islands, movements, culture, archipelago 


\section{MANIFIESTO TRASCENDENTALISTA}

El tema del "Manifiesto Trascendentalista", su visión mística—religiosa y espiritual, siempre — por alguna razón - nos atrae poderosamente. Varios motivos recurrentes nos sumergen en el análisis de este movimiento poético desde sus inicios en el 1948 mediante el "Manifiesto Trascendentalista" de Félix Franco Oppenheimer, Francisco Lluch Mora y Eugenio Rentas Lucas en la consabida revista Alma Latina en aquel 3 de julio de 1948 cuando se publica el Manifiesto Trascendentalista y, luego, surge un grupo de seguidores o de voces de nuestra literatura puertorriqueña que los respaldan y realizan diversas obras literarias. ${ }^{1}$

Más adelante en el tiempo — treinta y cinco años después- es cuando Luis O. Zayas Micheli publica Trascendentalismo e ideología en Puerto Rico (1983) ${ }^{2}$, un complejo y amplio estudio sobre este movimiento que vendrá a amplia el concepto que se tiene del trascendentalismo puertorriqueño, además de los prólogos y ensayos que han tratado el tema, por aquí y por allá.

Nuestro punto de vista desde el estudio que hemos realizado en la tesis doctoral aun inédita Existencialismo, trascendentalismo y dolor en la poesía de Adrián Santos Tirado (2016) ${ }^{3}$ es que el trascendentalismo puertorriqueño del 1948 se difundió a otras latitudes del Caribe inmediato como lo prueban los hallazgos de dos textos emblemáticos: La poesía contemporánea en Cuba (1927-1953) ${ }^{4}$ de Roberto Fernández Retamar ( tesis doctoral), la cual fue publicada en las Ediciones Orígenes por petición de José Lezama Lima en 1954 y, luego, se publica con algunas correcciones en forma de libro en el 2008. El otro texto que nos aborda y nos indica que el "Manifiesto trascendentalita puertorriqueño" de 1948 se divulgó por el Caribe parlante es el artículo titulado "El nacimiento del trascendentalismo y su significado" publicado en la revista Horizontes en 1996 por Félix Franco Oppenheimer. ${ }^{5}$

Estos textos nos llevan a reflexionar ampliamente, y a inferir, que las raíces del trascendentalismo puertorriqueño como movimiento teológico o espiritual del hombre se expandió, más allá, de lo que se pudo pensar en Puerto Rico —y por eso — Roberto Fernández Retamar en su tesis del 1953 y Félix Franco Oppenheimer en el artículo del 1996 cuando habla de la revista Surcos de la hermana República Dominicana; ambos autores -respectivamente en sus obras- dialogan sobre los poetas trascendentalistas.

Este hallazgo, es revelador, porque sostiene, afirma y señala que el Movimiento trascendentalita puertorriqueño del 1948 no tan sólo se difundió a las islas vecinas, sino que formó una "Escuela Trascendentalista" en la cuenca caribeña, la cual, aún no se ha estudiado porque ha pasado desapercibida, para muchos intelectuales, durante varias décadas; y máxime, cuando cada uno de sus autores poseen un sello personal y distintivo que lo caracteriza. Además, nos lleva a sostener que el "Manifiesto Trascendentalista" de la revista Alma Latina en 1948 es el iniciador del movimiento y, por ello, nos 
compete a todos los estudiosos puertorriqueños viajar sobre las páginas de la historia y develar hasta la saciedad este importante descubrimiento para las letras de nuestro país.

Cronológicamente hablando, si fuéramos a realizar la ordenación del Movimiento Trascendentalista del Caribe tendríamos que hablar del: "Manifiesto Trascendentalista" de la revista Alma Latina en 1948 por Félix Franco Oppenheimer, Francisco Lluch Mora y Eugenio Rentas Lucas; la reproducción del "Manifiesto Trascendentalista" en la revista dominicana Surcos en 1949; La poesía contemporánea en Cuba (1927-1953) de Roberto Fernández Retamar en 1954 y el libro Trascendentalismo e ideología en Puerto Rico (1983) de Luis O. Zayas Micheli. Debemos resaltar que La poesía contemporánea en Cuba (1927-1953) de Roberto Fernández Retamar sitúa el trascendentalismo cubano desde 1927 hasta 1953 con sus obras; además de ir en la búsqueda de los poetas que se establecen en dichos textos literarios.

Según lo que se desprende de nuestro estudio de investigación, en términos generales, los grupos trascendentalistas lo conforman los tres grupos de autores dentro de las islas caribeñas, y según se desprende de los textos arriba mencionados.

El tema del trascendentalismo en el Caribe todavía no se ha estudiado a cabalidad. Se entiende que esta investigación inicia una aproximación hacia ese estudio. Cuando se habla del tema en la cuenca del Caribe, se encuentra que para el año de 1948 las tres islas caribeñas (Cuba, República Dominicana y Puerto Rico) tienen un vínculo muy fuerte en torno al estudio del trascendentalismo.

El Movimiento Trascendentalista se presenta en las islas de Cuba, República Dominicana y Puerto Rico de diversas formas. No se ha podido expandir este análisis a las islas de Haití y Jamaica por las diferenciaciones lingüísticas de estas dos últimas islas. Tal vez exista una escaza relación con la producción literaria de las islas de Haití y Jamaica. Se infiere que puedan existir algunas correlaciones literarias entre las cinco islas caribeñas.

Félix Franco Oppenheimer (1996), plantea en la revista Horizontes lo siguiente:

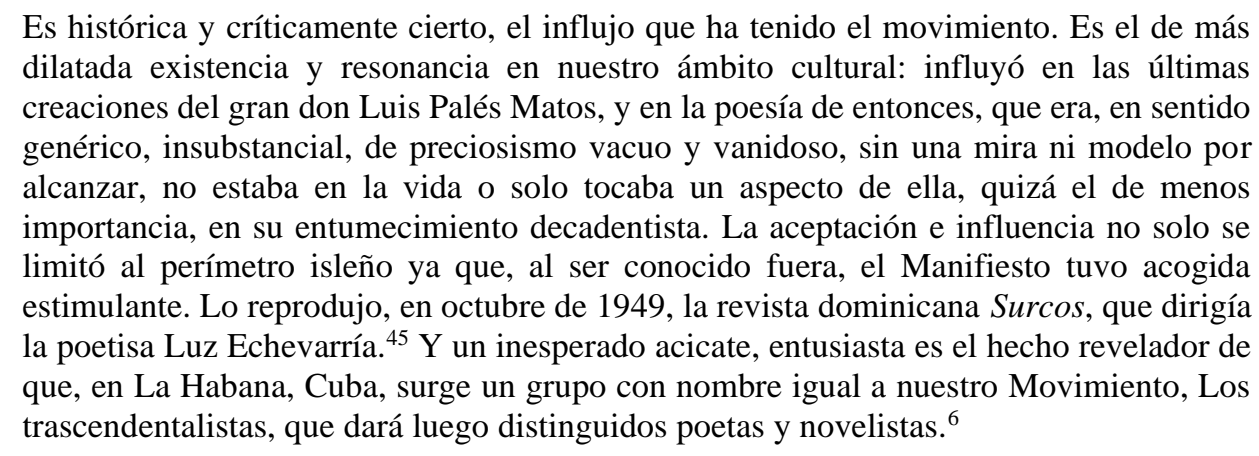

Desde este punto de vista hay que ver las repercusiones que el Movimiento Trascendentalista generó en las islas caribeñas. No siempre los pueblos valoran al máximo los estudios culturales y, muchas 
veces, la cultura se pierde porque no se rescata a tiempo. Esta cita de Félix Franco Oppenheimer es importante porque demuestra que el trascendentalismo se dio en las islas. El trascendentalismo en la cuenca del Caribe involucra un estudio más amplio del que se puede plantear en esta investigación aun cuando las creaciones procedan de diversas causas y males socio-políticos.

\title{
2 EL TRASCENDENTALISMO EN CUBA
}

Fernández Retamar en la obra La poesía contemporánea en Cuba (1927-1953) ${ }^{7}$, plantea y describe el surgimiento de la "Poesía Trascendentalista" en Cuba para el año de 1937:

\begin{abstract}
Este nuevo movimiento de nuestra poesía surge en 1937, año en que José Lezama Lima publica su poema Muerte de Narciso. Ya que hablamos de cómo Virgilio Piñera señaló, a propósito de esta obra, la aparición entre nosotros de una nueva actitud frente a la poesía: de una nueva generación. El mismo año en que publica su importante poema, Lezama edita Verbum, la primera de las revistas en que se manifestaría la generación; la más importante de aquellas fue, antes de Orígenes, Espuela de Plata. El propio Lezama ha hablado de la «generación de Espuela de Plata», dando así a entender la relevancia de esta publicación en que ya colaboraron Virgilio Piñera, Gastón Baquero, Ángel Gaztelu, Justo Rodríguez Santos y Cintio Vitier. En 1941 Lezama publica su libro Enemigo rumor, obra esencial por la influencia que tuvo en los restantes poetas de este movimiento. La generación se consolida - recordemos la importancia que prestó Petersen a las revistas - al aparecer en 1944 Orígenes, la más importante revista literaria cubana desde la Revista de Avance. En 1948, aparecidas ya obras definitivas dentro de esta tendencia, Citio Vitier realiza su antología (de que hablamos al principio del capítulo), en que muestra los más altos logros «de un trabajo poético que representa, junto al vigoroso movimiento pictórico que lo acompaña, la más secreta y penetradora señal de nuestra cultura en los últimos diez años». De entonces a la fecha, han aparecido libros que enriquecen esa labor, como La fijeza (1949) y Analecta del reloj (1953), de Lezama; Sustancia (1950), Conjeturas (1951) y Vísperas, 1938-1953 (1953), de Vitier; En la Calzada de Jesús del Monte (1949), de Diego, y Las miradas perdidas (1951), de Fina García Marruz. ${ }^{8}$
\end{abstract}

Roberto Fernández Retamar (1953), habla de las características esenciales de esta poesía en Cuba y señala: "Poesía la suya trascendente - en cuanto no se detiene morosamente en el deleite verbal, o considera al poema como intermediario de una exposición afectivo-conceptual, sino como «posible apoderamientos de lo desconocido», creemos que esta cualidad es la señal más definida de tal poesía, y la utilizamos para designarla". Indica además las relaciones directas e indirectas con "el vocablo trascendental", según lo plantea Kant, sin ignorar la "inmanencia de la literatura" según la postula Alfonso Reyes en el libro El deslinde (1944).

Por otro lado, Gastón Baquero en el ensayo "Tendencias actuales de nuestra literatura" (1944) 9 , la define como: "obra de creación que se asoma y alimenta en fuentes de metafísica, de religiosidad, de búsqueda penetrante en las zonas más ocultas de la vida espiritual. [...] obra casi hermética, casi críptica, pues tanto es lo que precisan recorrer e iluminar en lo oscuro".

Guillermo Torre (1951), indica al estudiar la poesía trascendentalista en Cuba que: 
..no se conforma ya con ser pura, con ser canto o plegaria, no le basta con ser antianecdótica, olvida uno de sus elementos capitales, la metáfora-hace dos décadas tan justamente traída a primer plano-; ahora quiere ser, cuando menos, trascendente, metafísica; quiere convertirse en una «actividad del espíritu» y hasta en un método de conocimiento. ${ }^{10}$

\section{EL TRASCENDENTALISMO EN LA REPÚBLICA DOMINICANA}

Por otro lado, el estudio de la "poesía trascendentalista” en la República Dominicana parte de los poetas que constituyen los siguientes movimientos literarios: Independientes del 40, la Poesía Sorprendida (1943-1947), los poetas Cuarentiochistas y los poetas Independientes del 48; los cuales son los escritores obligados de los grupos poéticos de la época del 1948. Estos escritores influirán, más adelante, en las producciones literarias de los escritores de la Generación del cincuenta (1950) y la Generación del 1960 en la República Dominicana. Entre los poetas representativos de estos movimientos encontramos a Pedro Mir (1912) con “Hay un país en el mundo”, Héctor Incháustegui Cabral (1912-1979) con "Diario de la guerra"; Manuel Rueda (1921) con "Plegaria de Caín”, Antonio Fernández Spencer con "Voy a escribir mis penas"; Abelardo Vicioso (1930) con “Génesis", Máximo Avilés Blonda (1931-1988) con "Memoria de Dios en el Sur"; y Juan Sánchez Lamouth (1929-1968) con "Los gritos y los tiempos".

Franklin Gutiérrez (2004) ${ }^{11}$ plantea que la “Generación del 1948 en la República Dominicana” se caracterizó por la creación de una poesía testimonial, esencialmente política, la cual recrea la historia. Es poesía para buscar y redescubrir el paisaje nacional. Esta poesía canta al hombre y a su destino transmutado en las dimensiones humanas y universales.

Afirma Gutiérrez en el estudio sobre la Generación del ‘48 en la República Dominicana, que desde el origen, el grupo de poetas que lo conformaba no tiene un nombre claro, puesto que cada uno la llamó de diversa forma. Por ejemplo, el poeta Avilés Blonda la llamó Generación del 48, al ser cuestionado por el poeta español Leopoldo Panero. Por otra parte, Víctor Villegas, prefirió el calificativo de Generación Integradora debido a que el objetivo de este grupo era integrar lo dominicano a lo universal. Valera Benítez sugirió el nombre de Generación de postguerra, en referencia a la Segunda Guerra Mundial. Mientras que Diógenes Céspedes y Alberto Baeza Flores coinciden en llamarlo Grupo del 48. Indistintamente de cómo se llamó al grupo de poetas, todos durante el año de 1948 produjeron una poesía testimonial, esencialmente política, que recrea la historia, busca las raíces sociológicas, redescubre y afianza el paisaje nacional. Según Franklin Gutiérrez (2004), el grupo estaba constituido por los poetas Máximo Avilés, Ramón Cifré Navarro, Abel Fernández Mejía, Lupo Hernández Rueda, Juan Carlos Jiménez, Rafael Valera Benítez, Luis Alfredo Torres, Abelardo Vicioso y Víctor Villegas.

Algunos de los postulados que destaca Franklin Gutiérrez del Grupo del 48 son los siguientes: "Se recogen aquellos productos del pensamiento dominicano que puedan situarse dentro de las exigencias del arte y de la ciencia", "Esto debe alcanzarse mediante la búsqueda e identificación con nuestras más 
pasibles esencias, como único medio para arribar a la expresión de las dimensiones universales del ser dominicano", "el hombre es el único ser sujeto de destino y la única criatura susceptible de plantearse el problema de su tránsito por el mundo" y "La poesía, «dado el tono humano de su procedencia», aunque sea universal e intemporal, tiene una grave y apasionada función a tono con un tiempo y un espacio dados".

Por otro lado, un dato importante que destaca Gutiérrez es que:

Los cuarentiochistas no tuvieron una revista literaria propia ni ningún medio de comunicación para difundir su producción, pero, en cambio, crearon la colección El Silbo vulnerado y aprovecharon las solapas de los primeros libros publicados para difundir los ideales y las metas del grupo. ${ }^{12}$

El estudio de la poesía trascendentalista en la zona caribeña lleva a pensar que estos poetas son los precursores de los grandes movimientos literarios que se darán en la Generación del 1960 y, de ahí, la importancia del estudio como movimientos y como escuelas literarias. El trascendentalismo literario está presente durante el año de 1948 en la mayoría de las antillas mayores de la zona caribeña. Es un movimiento de breve duración temporal pero de grandes alcances literarios. Tal vez el derrotero mayor de este movimiento fue que no se lograron realizar estudios sobre las diversas contribuciones literarias dentro de un marco histórico-literario de visión diacrónica y caribeña, lo cual por sí podría constituir en un tema de investigación.

\section{EL TRASCENDENTALISMO EN PUERTO RICO}

El 3 de julio de 1948 en la prestigiosa revista Alma Latina, un grupo de tres jóvenes escritores puertorriqueños — Félix Franco Oppenheimer, Eugenio Rentas Lucas y Francisco Lluch Mora— hicieron público para el pueblo puertorriqueño las bases del Manifiesto Trascendentalista. ${ }^{13}$ Los motivó la ideología de la renovación de las letras puertorriqueñas y en contra de los sucesos violentos de la Segunda Guerra Mundial (1939-1945),“el materialismo” y el avance del “cientificismo burgués” de aquella época. Lanzaron el manifiesto donde se declararon los siguientes postulados:

\footnotetext{
El trascendentalismo "anhela elevar al hombre a un plano de alta espiritualidad", el trascendentalismo será "integrador de la personalidad humana", surge como reacción al "materialismo y al cientificismo", la poesía del trascendentalismo "debe ser algo esencial trascendente que toque al ser en lo diáfano", están empeñados en "desarrollar una actitud trascendente para el logro de un arte humano"; el arte debe tener una "realidad trascendente, el hombre"; no creen en "un arte ausente o arte por el arte" y tratan de realizar "una obra de ancho aliento universal en que esté presente nuestra agonía". ${ }^{14}$
}

El panorama histórico al escribir el manifiesto no era muy alentador para las letras, según exponen en la declaración. Rutherford, en 1912 afirma, había descubierto la estructura del átomo y los científicos no habían descansado hasta crear "la bomba atómica", la cual describen como una "factura perversa y criminal, que a todos nos llena de pesimismo". Señalan además que hay una crisis de valores. Que el 
errado juicio de Ernesto Renán ha provocado esta "anormalidad de la ciencia". Entiende, al igual que Vicente Huidobro, que "el poeta es el puente que une al hombre con el universo" y señala al citar a Mario Abril, que "solo el poeta puede restablecer el equilibrio en el cosmos".

Muy bien ha resumido Félix Franco Oppenheimer el surgimiento del Movimiento Trascendentalista en los siguientes términos:

\begin{abstract}
Es mayo de 1948. Terminación de cursos. Los amigos poetas Rentas Lucas y Lluch Mora me hacen la visita de costumbre en la Editorial. En esta ocasión, en vez de quedarnos en la oficina a platicar sobre puntos de vista de nuestra cultura y proponer proyectos, decidimos ir a San Juan. Así lo hicimos, viajando en una guagua.

En San Juan después de recorrer varios pasajes de la ciudad murada se nos ocurrió visitar, en el cementerio, las tumbas de hombres ilustres nuestros. En la parte antigua, donde, frente a la capilla circular se destaca — entre otros - el busto en mármol del poeta José Gautier Benítez, el tal vez más representativo del romanticismo insular, nos detuvimos en reflexiones y simpatías de hondas emotividades. Como tras la blanca piedra se traslucía el semblante del cantor apasionado, se nos vino la idea de crear un movimiento sustentado en la postura y levantado espíritu de afirmación del hombre, en lugar de origen. Y así quedamos, moral e intelectualmente comprometidos, señalando las causas y finalidades específicas que, juramentamos, procuramos cumplir, atenidos a la realidad del instante de crisis en que vivía Puerto Rico y el mundo. ${ }^{15}$
\end{abstract}

Como filosofía de vida establecen que "se hace imperativo un reajuste de la vida puertorriqueña". Creen en una filosofía ecléctica, la cual "no sea extremista, ni pragmática, ni totalizante, ni concluyentemente idealista, sino que tenga equilibrio: el hombre". Más bien creen en la "metafísica de Aristóteles", "una ciencia del ser" en donde el hombre sea el eje central de todos los problemas de la vida, “de la representación, de la intuición y de la acción”. Esta filosofía, sostienen los poetas, debe basarse en "la fe en el individuo" y argumentan además que:

Debe negar el pesimismo de Jean Paul Sartre que piensa que el hombre no puede realizarse y que el encontrarse a sí mismo, significaría el desengaño de que nada existe y que con su muerte todo terminará. ${ }^{16}$

Finalmente, concluyen en la nueva filosofía que la finalidad última está basada en "el sentir agónico del hombre” y que el poeta es el "poseedor de la visión trascendente, y es además el que intuye, el que comunica, creen que es él, el llamado a realizar esta obra suprema”.

En el manifiesto, los tres poetas, realizan un apretado recuento de los diversos movimientos literarios en Puerto Rico hasta entonces: las corrientes modernistas, movimiento Pancalista de Lloréns Torres, el Diepalismo, exaltan el "Canto al tornillo" como embrión de la poesía negroide, movimiento poético surrealista de Salvador Dalí, el Noísmo de Vicente y Gustavo Palés Matos, hablan de la revista Índice, Alma Latina, Brújula, la Atalaya de los dioses, el Integralismo y termina con el trascendentalismo poético que es el movimiento que proponen. 
Dentro del trascendentalismo poético se alejan del movimiento trascendentalista de Ralph Waldo Emerson, ya que entiende que el de ellos es un trascendentalismo que tiene "algunas tangencias ideológicas con el de Emerson". Pues el trascendentalismo puertorriqueño tiene una visión integradora de la personalidad y tiene cierto "humanismo romántico", el cual conciben como "un estado permanente del espíritu humano". Están de acuerdo en que aceptan el romanticismo inglés y el alemán, pero afirman que el trascendentalismo poético que proponen, "debe despertar en el hombre actual una inquietud superior".

La poética de este trascendentalismo puertorriqueño se presenta como una que sirva al hombre. Señalando que Ortega y Gasset ha dicho, "la poesía y todo arte versa sobre lo humano y sólo sobre lo humano". Afirman que "la poesía está en la intimidad de los seres y las cosas". Según Novalis, "la poesía es la esencia más íntima de la realidad”. Indican además que:

La poesía no es la alegría brilladora, estéril. La poesía es más bien un deslumbre interior, una angustia gozosa; es hasta cierto punto, dolor... Y la gracia, sólo la poseen los que saben de la infinita dimensión del dolor y el imposible, que late en la insondable perspectiva del espíritu... No podía ser de otro modo ya que como nos dice Antonio Machado "la poesía es la palabra esencial en el tiempo". ${ }^{17}$

Por otro lado, José Emilio González (1955), afirma en el ensayo "La poesía puertorriqueña 19301954" que "hay serias razones para dudar de que se trate de un nuevo movimiento, propiamente, en nuestra poesía".

En este año un grupo de poetas jóvenes -Félix Franco Oppenheimer, Eugenio Rentas Lucas y Francisco Lluch Mora - fundan otro "movimiento" que bautizan con el nombre de "trascendentalismo". En su manifiesto inicial proclaman que el trascendentalismo "anhela elevar al hombre a un plano de alta espiritualidad, sin olvidar su realidad humana" y aspira a ser "integrador de la personalidad”. Es una reacción contra el "cientificismo sin entrañas, desolador y burgués" y contra "el materialismo sórdido que estrangula al mundo". Quieren "crear un arte fuerte en su estructura y en su estética, equilibrado en la condición humana. El arte debe tener una realidad trascendente, el hombre". Prometen: "Trataremos de realizar una obra de ancho aliento universal en que esté presente nuestra agonía". Los bardos de este grupo, a los cuales se sumó Ramón Zapata Acosta, han publicado sus libros en la Colección Yaurel. También sacaron una revista, "Pegaso". Sin embargo, hay serias razones para dudar de que se trate de un nuevo movimiento, propiamente, en nuestra poesía. ${ }^{18}$

No tan solo se entiende que el Movimiento Trascendentalista fue un "movimiento literario puertorriqueño", y valga la redundancia, sino que se opina que fue "una escuela literaria fundacional en la literatura puertorriqueña", tanto es así, que los hechos y los acontecimientos hablan por sí solos.

Por otra parte, Francisco Lluch Mora en el ensayo “Trascendentalismo y existencialismo” señala que:

Los autores, casi todos jóvenes, cuyo centro de interés era la Universidad para los años del 1945 al 50, unos, poetas, otros, ensayistas, cuentistas, novelistas, etc., cuyo centro de interés era la dinámica humanística, dentro de la filosofía existencial-trascendentalista, son, entre otros, además de los citados fundadores y firmantes del Manifiesto Trascendentalista del 1948: Francisco Matos 
Paoli, Eugenio Fernández Méndez, Ricardo Alegría, Juan Martínez Capó, Julio César López, Lilliam Pérez Marchand, Gerald-Paul Marín, Rafael Antonio González Torres, Francisco Rivera Landrón, Laura Gallego, Violeta López Suria, Nimia Vicéns, Monalisa Lina Pérez Marchand, Ana Inés Bonnín Amstrong residente en Barcelona, Miguel A. Quirós, Francisco Rojas Tollinchi, Ramón Zapata Acosta, Jorge Luis Morales, José A. Hernández, Héctor Campos Parsi, José Gil Lamadrid, Héctor Landrón Ubiñas, Noel Colón Martínez, Juan Mari Bras, José Luis González, Abelardo Díaz Alfaro, Luis Miranda Correa, César Andreu Iglesia, Rubén Gotay Montalvo, Héctor Barrera, Juan Enrique Colberg, Ester Feliciano Mendoza, Wilfredo Braschi, Aníbal Díaz Montero, Roberto Díaz Nadal, Néstor A. Rodríguez Escudero, René Marqués, Pedro Juan Soto, Ángel Rigau, Olga Ramírez de Arellano de Nolla, Diana Ramírez de Arellano, Elia Sulsona, Francisco Arriví, Manuel Joglar Cacho, José Luis Marín, etc. ${ }^{19}$

No obstante, cuando se sostiene que el movimiento trascendentalista fue una escuela es porque varios conceptos se replicarán más adelante en la literatura puertorriqueña y entre los escritores de las próximas generaciones. Estos conceptos son: “dolor, angustia, agonía, la reflexión religiosa sobre la existencia de Dios y el hombre, el hombre como tema central de la poesía, los temas de lo humano y la deshumanización en la literatura, la muerte y el cuestionarse la existencia misma después de la muerte". Para probar este planteamiento solo hay que colocar los hechos aislados o separados que nadie ha colocado, juntos hasta ahora, para ver por qué este movimiento trascendentalista es una escuela fundacional de la literatura puertorriqueña.

En primer lugar, desde la década de 1940 se notaron señales del cambio que va tomando la literatura puertorriqueña y los escritores. Surge la Segunda Guerra Mundial (1939-1945). En la década del 1940, Luis Hernández Aquino publica el poemario Isla para la angustia: poemas integrales (1943). Desde ya se adelanta el tema de la angustia en la literatura puertorriqueña. Aunque Hernández Aquino lo hace desde el Movimiento Integralista al cual perteneció, no será hasta los postulados del Movimiento Trascendentalista que se forma la escuela y surgen los primeros seguidores de la escuela en la próximas dos décadas de 1950 y 1960. Será a partir de la publicación de los libros Mañana en el alba (1949), de Eugenio Rentas Lucas, Del asedio y la clausura (1950), de Francisco Luch Mora y El hombre y su angustia (1950) de Félix Franco Oppenheimer ${ }^{18}$ cuando se avivan las incursiones en el tema trascendentalista de Puerto Rico.

\section{CONCLUSIÓN}

A la conclusión que podemos llegar es que el tema de El trascedentalismo en el Caribe parte desde 1927 en Cuba según la investigación de Roberto Fernández Retamar, quien presenta su tesis doctoral el 23 de noviembre de 1953 en La Habana, Cuba, pero cinco años antes, los poetas puertorriqueños habían publicado el "Manifiesto Trascendentalista" en 1948, y desde ese entonces, se había comenzado a difundir por todo el Caribe hispánico según lo confirman las revistas: Alma Latina y 
Surcos. Queda para los futuros investigadores el estudiar las obras de este movimiento o escuela poéticaliteraria desde las perspectivas místicas y religiosas de nuestros tiempos.

\section{OBRAS CITADAS}

1 Franco Oppenheimer, F., Rentas Lucas, E. y Lluch Mora, F. (1948). "Manifiesto Trascendentalista". Alma Latina. Julio-Agosto. 3 de julio de 1948.pp. 6-7.

2 Zayas Micheli, L. O. (1983). Trascendentalismo e ideología en Puerto Rico. Ediciones Mairena, San Juan, PR. pp.189.

3 Segarra Báez, I. (2016). Existencialismo, trascendentalismo y dolor en la poesía de Adrián Santos Tirado. Centro de Estudios Avanzados de Puerto Rico y el Caribe, San Juan, P.R. Tesis doctoral inédita: recomendada para publicar. pp. 347.

4 Fernández Retamar, R. La poesía contemporánea en Cuba (1927-1953). La Habana, Cuba. Editorial Instituto Cubano del libro. (2009). pp. 113-114.

5 Franco Oppenheimer, F. (1996). "El nacimiento del trascendentalismo y su significado". Revista Horizontes. Universidad Católica de Ponce, Puerto Rico. Año XXXVIII. Núm. 75. Octubre, pp. 82.

6 Ob. Cit., pág. 82.

7 Fernández Retamar, R. La poesía contemporánea en Cuba (1927-1953). La Habana, Cuba. Editorial Instituto Cubano del libro. (2009). pp. 113-114.

8 Se refiere a la antología Diez poetas cubanos de Citio Vitier, La Habana, Cuba. (1948).

9 Gastón. B. (1994). “Tendencias actuales de nuestra literatura”. En Anuario Cultural de Cuba, 1943. La Habana, Cuba. pp. 266-267.

10 De Torre, G. (1948). Problemática de la literatura. Buenos Aires, República Argentina.

11 Gutiérrez, F. (2004). “Generación del 48”. Diccionario de la literatura dominicana: biográfico y terminológico. Editora Búho. Santo Domingo, República Dominicana. pág. 190.

12 Ob. Cit., pág. 191.

13 Franco Oppenheimer, F., Rentas Lucas, E. y Lluch Mora, F. (1948). "Manifiesto Trascendentalista". Alma Latina. Julio-Agosto. 3 de julio de 1948.pp. 6-7.

14 Ibíd., págs. 6, 7, 10, 16 y 33.

15 Franco Oppenheimer, F. (1996). "El nacimiento del trascendentalismo y su significado". Horizontes. Universidad Católica de Puerto Rico. Año XXXVIII. Núm. 75. Octubre. Ponce, P.R. pp. 79-80.

16 Op. Cit., págs. 6-7. 
17 Op. Cit., pág. 16.

18 González, J. E. (1995). “La poesía puertorriqueña de 1930-1954”. Asomante. Enero-Marzo, Núm. 1, San Juan, P.R., pp. 86-87.

19 Lluch Mora, F. (1996). "Trascendentalismo y existencialismo". Revista Horizonte. Universidad Pontificia Universidad Católica de Puerto Rico. Año XXXVIII. Núm. 75. Octubre. Ponce, P.R., pp. 6970. 